\title{
Efeito da adubação nitrogenada de cobertura e do espaçamento sobre a produção de rúcula
}

\author{
Luis Felipe Villani Purquerio ${ }^{1}$; Luis Alfredo Rauer Demant ${ }^{2}$; Rumy Goto² ${ }^{2}$ Roberto Lyra Villas Boas ${ }^{3}$ \\ ${ }^{1}$ Instituto Agronômico, Centro de Horticultura, C. Postal 28, 13012-970 Campinas-SP; ${ }^{2}$ UNESP-FCA, Produção Vegetal/Horticultura; \\ ${ }^{3}$ UNESP-FCA, Recursos Naturais/Ciência do Solo C. Postal 237, 18603-970 Botucatu-SP; felipe@iac.sp.gov.br
}

\section{RESUMO}

Conduziu-se experimentos para avaliar a influência da adubação nitrogenada em cobertura (0; 60; 120; 180 e $240 \mathrm{~kg} \mathrm{ha}^{-1}$ de N), fornecida via fertirrigação e do espaçamento entre plantas $(0,05$; 0,07 e $0,10 \mathrm{~m}$ ), na rúcula, cultivada dentro e fora de ambiente protegido. O delineamento experimental utilizado foi de parcelas subdivididas, com quatro repetições. Nos experimentos de outono/inverno e nos de verão, verificou-se resposta crescente para a área foliar, massa de matéria seca (MMS), produtividade e teor de nitrato no extrato foliar com o aumento das doses de $\mathrm{N}$. As plantas espaçadas de 0,10 m apresentaram maiores médias de área foliar e MMS, porém a maior produtividade foi encontrada no espaçamento de 0,05 $\mathrm{m}$, devido ao maior número de plantas por área. No outono/inverno, a dose de $\mathrm{N}$ que possibilitou a maior produtividade no campo foi de $240 \mathrm{~kg} \mathrm{ha}^{-1} \mathrm{e}$ no ambiente protegido foi de $178,6 \mathrm{~kg} \mathrm{ha}^{-1}$. No verão, no ambiente protegido, as doses estimadas de $\mathrm{N}$ que possibilitaram maiores produtividades nos espaçamentos de 0,05; 0,07 e $0,10 \mathrm{~m}$ foram 240; 167,3 e $231 \mathrm{~kg} \mathrm{ha}^{-1}$, respectivamente.

Palavras-chave: Eruca sativa, nitrogênio, nutrição de plantas, nitrato, sistema de produção.

\section{ABSTRACT}

Effect of side dressing nitrogen fertilization and distance between plants on yield of rocket salad

Experiments were carried out to investigate the effects of nitrogen side dressing fertilization $\left(0 ; 60.0 ; 120.0 ; 180.0\right.$ and $\left.240.0 \mathrm{~kg} \mathrm{ha}^{-1}\right)$, applied by fertigation and distance between plants $(0.05 ; 0.07$ and $0.10 \mathrm{~m}$ ) for rocket salad in the field and greenhouse. The experimental design was a split-plot with randomized blocks, replicated four times. In the autumn/winter and summer experiments occurred an increase in leaf area, dry mass weight, yield and content of nitrate in leaves extract with an increase of the $\mathrm{N}$ doses applied. Plants spaced at $0.10 \mathrm{~m}$ presented the highest average leaf area and dry mass weight, but the highest yield was obtained with $0.05 \mathrm{~m}$ space, due to the high number of plants/area. In the autumn/winter cropping, the side dressing $\mathrm{N}$ application rate that allowed the highest yield in field was $240.0 \mathrm{~kg} \mathrm{ha}^{-1}$ and in greenhouse $178.6 \mathrm{~kg} \mathrm{ha}^{-1}$. In the summer, in greenhouse, the estimated side dressing nitrogen application rate that allowed the highest yield under plant spaced of 0.05, 0.07 and 0.10 m were 240.0, 167.3 and $231.0 \mathrm{~kg} \mathrm{ha}^{-1}$, respectively.

Keywords: Eruca sativa, nitrogen, plant nutrition, nitrate, production system.

(Recebido para publicação em 28 de março de 2006; aceito em 30 de agosto de 2007)

$\mathrm{D}$ entre as hortaliças folhosas, a alface é a mais plantada e a mais consumida pela população brasileira. Porém, desde o final da década de 90 , a rúcula vem conquistando espaço no mercado. Na Companhia de Entrepostos e Armazéns Gerais do Estado de São Paulo (CEAGESP), a quantidade de rúcula comercializada teve um crescimento de $78 \%$ de 1997 a 2003 (Silva, 2004). Esse crescimento foi superior ao da alface (americana e crespa), que apresentou $40 \%$ de aumento no mesmo período. Outro aspecto relevante diz respeito a sua valorização na CEAGESP. Em 2003 apresentou preço anual médio de $R$ \$ 2,43 $\mathrm{kg}^{-1}$ em comparação a $\mathrm{R} \$$ $0,64 \mathrm{~kg}^{-1}$ obtido pela alface (média dos tipos americana e crespa). O crescimento na quantidade comercializada e a sua valorização na cotação são indicadores de que a rúcula é rentável. Contudo, apesar de sua importância econômica para a horticultura, existem poucos estudos relacionados ao manejo da nutrição mineral e ao espaçamento entre plantas.

Sendo a rúcula uma hortaliça folhosa, sua adubação nitrogenada torna-se de grande importância. Na região do Vêneto, na Itália, Baggio \& Pimpini (1995), citado por Pimpini \& Enzo (1997), realizaram ensaios com aplicação de doses de $\mathrm{N}$ na rúcula em campo e verificaram maior produtividade com o uso $100 \mathrm{~kg} \mathrm{ha}^{-1}$. Posteriormente, os autores complementaram essa informação citando que no cultivo em ambiente protegido com mais de um corte, ou em solos arenosos, deve-se usar $200 \mathrm{~kg} \mathrm{ha}^{-1}$ de $\mathrm{N}$ na adubação da rúcula. No Brasil, são escassas as informações sobre a nutrição da rúcula. Muitas vezes os resultados de pesquisas obtidos para a alface são utilizados como orientação para a realização da adubação dessa cultura (Katayama, 1993). As recomendações de adubação nitrogenada, encontradas na literatura para a rúcula não fazem distinções entre famílias e espécies. Camargo (1992) recomenda para a rúcula, juntamente com mais 11 culturas de famílias e espécies distintas a aplicação $30 \mathrm{~kg} \mathrm{ha}^{-1}$ de $\mathrm{N}$ no plantio e mais $120 \mathrm{~kg} \mathrm{ha}^{-1} \mathrm{de} \mathrm{N}$ em cobertura, em doses iguais, aos dez, vinte e trinta dias após o transplante ou emergência das plântulas (DAE). Trani \& Raij (1996) também recomendam para alface, almeirão, chicória, escarola, rúcula e agrião d'água, a aplicação de $40 \mathrm{~kg} \mathrm{ha}^{-1}$ de $\mathrm{N}$ no plantio e especificamente para rúcula, $120 \mathrm{~kg} \mathrm{ha}^{-1}$ de $\mathrm{N}$ em cobertura, parcelados aos sete, quatorze e vinte e um DAE. Não existe recomendação diferenciada entre os sistemas de produção em campo e em ambiente protegido. Faz-se então necessária a determinação de doses de $\mathrm{N}$ a serem utilizadas nos diferentes sistemas de produção, 
onde se insere o cultivo em ambiente protegido com uso de fertirrigação, bem como a validação dos resultados encontrados nos trabalhos existentes com a cultura em campo.

A população de plantas por unidade de área é determinada por três critérios básicos, que são o espaçamento entre fileiras, entre plantas e o número de plantas por cova. Diferenças nesses componentes podem influenciar as plantas, afetando-lhes a arquitetura, o desenvolvimento, a fitomassa, a qualidade e principalmente a produtividade (Mondim, 1988). A maior vantagem dos plantios adensados é o ganho de produtividade com menor custo de produção. Porém, quando se aumenta a população por unidade de área, cada planta começa a competir por recursos de crescimento. A resposta das plantas, depois de iniciada a competição, está ligada a fatores como espécies, cultivares, doses de adubação, irrigação e esquema de plantio (Mondim, 1988). Com a diminuição do espaçamento entre plantas ou com o aumento do número de plantas por área, a quantidade de fertilizante deve ser incrementada de modo a permitir o adequado desenvolvimento das plantas (Coutinho et al., 1993). Para a cultura da rúcula, Takaoka \& Minami (1984) observaram que o consumo de $\mathrm{N}$ por área foi maior nos menores espaçamentos utilizados. No sistema de cultivo em campo, com semeadura em canteiros definitivos, o espaçamento utilizado para a rúcula é de 0,20 a 0,30 m entre linhas e aproximadamente 0,05 a 0,10 m entre plantas, após o desbaste (Trani et al., 1992). Porém não existem informações de espaçamento entre plantas em outros sistemas de cultivo como em ambiente protegido. O objetivo do presente trabalho foi determinar a dose de $\mathrm{N}$ em cobertura fornecida via fertirrigação associada ao espaçamento entre plantas para maximizar a produtividade da rúcula cultivada em campo e em ambiente protegido, em duas épocas distintas, outono/inverno e verão.

\section{MATERIAL E MÉTODOS}

Os experimentos com a cultura da rúcula, um em campo e outro em ambiente protegido (simultâneos e inde- pendentes um do outro), foram conduzidos na transição outono/inverno de 31/ 05 a 7/07/2003. Posteriormente, outros dois foram realizados, um no campo e outro em ambiente protegido no verão de 19/01 a 21/02/2004, em área pertencente à FCA/UNESP, Campus de Botucatu em S. Manuel-SP. Utilizou-se uma estrutura do tipo arco, com 3,0 m de altura de pé-direito e 7,0 x 40,0 m, construída em ferro galvanizado, coberta com filme de polietileno de baixa densidade anti-UV de $150 \mathrm{~mm}$ de espessura e fechada lateralmente com tela de sombreamento de 30\%. A área de campo utilizada para os experimentos ficou distanciada de aproximadamente $60 \mathrm{~m}$ do ambiente protegido. O solo foi classificado como Latossolo Vermelho Amarelo fase arenosa segundo Espíndola et al. (1974). As análises físicas, realizadas pelo Laboratório de Fertilidade do Solo da FCA/UNESP, indicaram 900 e $873 \mathrm{~g} \mathrm{~kg}^{-1}$ de areia, 34 e $52 \mathrm{~g} \mathrm{~kg}^{-1}$ de silte e 66 e $75 \mathrm{~g} \mathrm{~kg}^{-1}$ de argila no campo e no ambiente protegido, respectivamente. As análises químicas para o cultivo de outono/inverno, no campo e no ambiente protegido indicaram respectivamente $\mathrm{pH}=5,1$ e 6,$4 ; 31$; $\mathrm{H}+\mathrm{Al}=11 \mathrm{mmol}_{\mathrm{c}} \mathrm{dm}^{-3} ; \mathrm{P}=17$ e $39 \mathrm{mg}$ $\mathrm{dm}^{-3} ; \mathrm{K}=1,0$ e $1,0 \mathrm{mmol}_{\mathrm{c}} \mathrm{dm}^{-3} ; \mathrm{Ca}=28$ e $23 \mathrm{mmol}_{\mathrm{c}} \mathrm{dm}^{-3} ; \mathrm{Mg}=12$ e $19 \mathrm{mmol}_{\mathrm{c}}$ $\mathrm{dm}^{-3} ; \mathrm{SB}=40$ e $43 \mathrm{mmol} \mathrm{dm}^{-3}$; CTC= 71 e $54 \mathrm{mmol} \mathrm{dm}^{-3} ; \mathrm{V} \%=57$ e $80 \mathrm{mmol}$ $\mathrm{dm}^{-3} ; \mathrm{MO}=23$ e $7 \mathrm{~g} \mathrm{dm}^{-3} ; \mathrm{B}=0,10$ e 0,06 $\mathrm{mg} \mathrm{dm}^{-3} ; \mathrm{Cu}=1,2$ e $0,7 \mathrm{mg} \mathrm{dm}^{-3} ; \mathrm{Fe}=43$ e 10 de $\mathrm{mg} \mathrm{dm}^{-3} ; \mathrm{Mn}=0,6$ e 5,4 $\mathrm{mg} \mathrm{dm}^{-3}$ e $\mathrm{Zn}=0,6$ e $1,7 \mathrm{mg} \mathrm{dm}^{-3}$. Para o cultivo de verão, os resultados das análises químicas de solo no campo e no ambiente protegido foram, respectivamente: $\mathrm{pH}=$ 6,1 e 5,8; $\mathrm{H}+\mathrm{Al}=11$ e $18 \mathrm{mmol}_{\mathrm{c}} \mathrm{dm}^{-3}$; $\mathrm{P}=60$ e $100 \mathrm{mg} \mathrm{dm}^{-3} ; \mathrm{K}=2,7$ e 5,3 $\mathrm{mmol}_{\mathrm{c}} \mathrm{dm}^{-3} ; \mathrm{Ca}=16$ e $34 \mathrm{mmol}_{\mathrm{c}} \mathrm{dm}^{-3}$; $\mathrm{Mg}=10$ e $10 \mathrm{mmol}_{\mathrm{c}} \mathrm{dm}^{-3} ; \mathrm{SB}=28$ e 49 $\mathrm{mmol}_{\mathrm{c}} \mathrm{dm}^{-3} ; \mathrm{CTC}=40$ e $67 \mathrm{mmol} \mathrm{dm}^{-3}$; $\mathrm{V} \%=71$ e $73 \mathrm{mmol}_{\mathrm{c}} \mathrm{dm}^{-3} ; \mathrm{MO}=7$ e 10 $\mathrm{g} \mathrm{dm}^{-3} ; \mathrm{B}=0,15$ e $0,13 \mathrm{mg} \mathrm{dm}^{-3} ; \mathrm{Cu}=$ 0,9 e 1,5 de $\mathrm{mg} \mathrm{dm}^{-3} ; \mathrm{Fe}=11$ e $21 \mathrm{de} \mathrm{mg}$ $\mathrm{dm}^{-3} ; \mathrm{Mn}=7,9$ e 8,0 de $\mathrm{mg} \mathrm{dm}{ }^{-3}$ e $\mathrm{Zn}=$ 2,5 e $6,2 \mathrm{mg} \mathrm{dm}^{-3}$.

O delineamento experimental utilizado foi de parcelas subdivididas, com quatro repetições, onde os tratamentos principais (parcelas) foram cinco doses de N (0;60;120;180; $\left.240 \mathrm{~kg} \mathrm{ha}^{-1}\right)$, fornecidas via fertirrigação em cobertura e os secundários (sub-parcelas), três espaçamentos entre plantas $(0,05 ; 0,07$ e $0,10 \mathrm{~m}$ ). A dose de $120 \mathrm{~kg} \mathrm{ha}^{-1} \mathrm{~N}$, recomendada por Trani \& Raij (1996) para cobertura nitrogenada em rúcula, foi utilizada como dose central, servindo de base para a determinação das outras quatro doses, duas acima e duas abaixo. Cada sub-parcela apresentou $1,5 \mathrm{~m}$ de comprimento e quatro linhas de plantas, espaçadas de 0,25 m. Nas duas épocas, coletaram-se dados de pluviosidade (mm) no campo, através de sensores, ligados a um micrologger, modelo CR23X (Campbell).

O solo foi preparado com enxada rotativa dentro do ambiente protegido e com arado e grade no campo. Os canteiros no ambiente protegido foram levantados manualmente e no campo com auxílio de roto-encanteirador. A correção do solo e a adubação de plantio foram realizadas com base em análise, seguindo-se a recomendação de adubação e calagem para o estado de São Paulo (Trani \& Raij, 1996). Para tanto, a calagem foi calculada para elevar a saturação por bases a 80\%. O calcário dolomítico foi aplicado 30 dias antes do transplante das mudas. Na adubação de plantio, para cada experimento, utilizouse $40 \mathrm{~kg} \mathrm{ha}^{-1}$ de $\mathrm{N}$ na forma de sulfato de amônio (20\% N). Utilizou-se também termofosfato magnesiano com adição de micronutrientes $\left(17 \% \mathrm{P}_{2} \mathrm{O}_{5}\right)$ e cloreto de potássio $\left(58 \% \mathrm{~K}_{2} \mathrm{O}\right)$ como fontes de fósforo e potássio, respectivamente. No outono/inverno, foi aplicado o equivalente a 2.352,9 e $1.764,7 \mathrm{~kg} \mathrm{ha}^{-1}$ de termofosfato no campo e no ambiente protegido, respectivamente e 258,6 kg $\mathrm{ha}^{-1}$ de cloreto de potássio nas duas áreas de cultivo. No verão foi utilizado o equivalente a $1.176 \mathrm{~kg} \mathrm{ha}^{-1}$ de termofosfato nos dois ambientes e 172,6 e 86,2 kg $\mathrm{ha}^{-1}$ de cloreto de potássio no campo e no ambiente protegido, respectivamente. Com relação à adubação orgânica, utilizou-se 20 t ha $^{-1}$ de esterco curtido de curral nos experimentos, conforme recomendação de Villas Bôas (2003). A caracterização química do fertilizante orgânico indicou 2,4; 2,8; 3,7; 25,5; 2,4; 0,9; 0,7; 46,0 e 72,0\% de $\mathrm{N}, \mathrm{P}_{2} \mathrm{O}_{5}, \mathrm{~K}_{2} \mathrm{O}$, $\mathrm{C}, \mathrm{Ca}, \mathrm{Mg}, \mathrm{S}, \mathrm{MO}$ e umidade, respectivamente. Após a realização dos experi- 
Tabela 1. Área foliar, massa de matéria seca (MMS) e produtividade de rúcula cv. Folha Larga, em campo (C) e ambiente protegido (AP), no outono/inverno, em função do espaçamento entre plantas (leaf area, dry mass weight (MMS) and yield of rocket salad cv. Folha Larga, in field (C) and greenhouse (AP), in autumn/winter, depending on plant spacing). FCA-UNESP, Botucatu, 2003.

\begin{tabular}{|c|c|c|c|c|c|c|}
\hline \multirow[t]{2}{*}{ Tratamento } & \multicolumn{2}{|c|}{$\begin{array}{l}\text { Área foliar } \\
\left(\mathrm{cm}^{2} \mathrm{~m}^{-2}\right)\end{array}$} & \multicolumn{2}{|c|}{$\begin{array}{l}\text { MMS } \\
\left(\mathrm{g} \mathrm{m}^{-2}\right)\end{array}$} & \multicolumn{2}{|c|}{$\begin{array}{l}\text { Produtividade } \\
\left(\mathrm{kg} \mathrm{m}^{-2}\right)\end{array}$} \\
\hline & C & AP & C & AP & C & AP \\
\hline $0,05 \mathrm{~m}$ & $42988,6 b^{1}$ & $50251,4 \mathrm{~b}$ & $159,4 \mathrm{c}$ & $169,7 \mathrm{c}$ & $2,91 \mathrm{a}$ & $3,30 \mathrm{a}$ \\
\hline $0,07 \mathrm{~m}$ & $47702,9 \mathrm{~b}$ & $53668,6 \mathrm{~b}$ & $184,0 \mathrm{~b}$ & $192,0 \mathrm{~b}$ & $2,35 \mathrm{~b}$ & $2,80 \mathrm{~b}$ \\
\hline $0,10 \mathrm{~m}$ & 53600,0 a & 59131,4 a & 210,3 a & 214,9 a & $2,05 \mathrm{c}$ & $2,27 \mathrm{C}$ \\
\hline CV\% & 13,74 & 11,65 & 13,16 & 13,82 & 14,60 & 15,83 \\
\hline
\end{tabular}

${ }^{1}$ Médias na coluna, seguidas de mesma letra, não diferem entre si, pelo teste de Tukey (5\% probabilidade) (means in the column, followed by the same letter, did not differ from each other, Tukey's test, $\mathrm{p}<0.05$ ).

mentos de outono/inverno, foram feitas irrigações aplicando-se lâminas de água superiores a $100 \mathrm{~mm}$, através de aspersão e gotejamento, para que houvesse a lixiviação dos nutrientes, principalmente do N, antes da realização dos experimentos de verão. Para o fornecimento de água e fertilizante nitrogenado (nitrato de amônio), em cobertura, nos experimentos foi utilizado um sistema de irrigação por gotejamento. Foram colocadas três linhas de gotejadores em cada canteiro, com espaçamento de $25 \mathrm{~cm}$. Para total controle do tratamento principal (doses de $\mathrm{N}$ ), instalaram-se registros no início de cada parcela correspondente, permitindo com isso, a aplicação da dose desejada de fertilizante nitrogenado. Nas irrigações, foi mantida a umidade do solo próxima à capacidade de campo mediante monitoramento com tensiômetros. A adubação de cobertura foi dividida em oito vezes nos experimentos de outono/inverno, sendo iniciada quatro dias após o transplante das mudas. Já nos experimentos de verão foi dividida em sete vezes, sendo iniciada três dias após o transplante das mudas.

Para a formação das mudas utilizouse bandejas de poliestireno expandido com 288 células, preenchidas com substrato (Plantmax HA). Em cada célula foram colocadas quatro sementes da cv. Folha Larga (TopSeed), com o intuito de padronizar o número de plantas por célula. O transplante ocorreu em 13/ 07/2003 no inverno e 01/02/2004 no verão. O manejo fitossánitario dos experimentos para o controle de pragas e doenças foi feito conforme necessário seguindo as recomendações do Depto. de Produção Vegetal/Defesa Fitossanitária da FCA/UNESP.

Após 37 dias da semeadura (DAS) no outono/inverno e 33 DAS no verão, realizou-se a colheita. Avaliaram-se a) área foliar de 16 plantas por sub-parcela, através de um integrador de área foliar (LI-COR, LI 3000); b) massa de matéria seca, através da secagem da parte aérea de 20 plantas por sub-parcela, em estufa de circulação forçada de $\operatorname{ar}\left(60^{\circ} \mathrm{C}\right)$; c) produtividade, considerando a massa de matéria fresca da parte aérea das plantas colhidas; d) teor de nitrato no extrato foliar das plantas, avaliado aos 36 DAS no outono/inverno e aos 32 DAS no verão, através de medidor de íons compacto, portátil, Nitrato Cardy (Horiba). Nas avaliações realizadas, sempre das 8:00 às 10:30 horas uniformizou-se a posição das folhas coletadas, apanhando-se quatro a seis folhas expandidas e basais de diferentes plantas de cada sub-parcela. As folhas foram esmagadas e algumas gotas do extrato obtido foram colocadas sobre o eletrodo do equipamento, para a realização da leitura. As leituras fornecidas pelo aparelho, expressas em

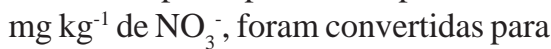
$\mathrm{mg} \mathrm{kg}^{-1}$ de $\mathrm{N}_{-} \mathrm{NO}_{3}^{-}$, dividindo-se o primeiro valor por 4,43 (Burt et al., 1995), para facilitar a comparação dos dados obtidos com os existentes em literatura. Os resultados das características avaliadas foram analisados estatisticamente através da análise de variância com teste F em cada experimento. Quando houve significância para o fator dose de N, foi feita análise de regressão, definindo o melhor ajuste segundo combinação de significância e maior coeficiente de determinação. Quando houve efeito do espaçamento entre plantas foi aplicado o teste de Tukey (5\%) para a comparação de médias. Quando ocorreu interação entre os tratamentos, o efeito dos espaçamentos foi estudado para cada dose de $\mathrm{N}$.

\section{RESULTADOS E DISCUSSÃO}

Cultivo de outono/inverno - $\mathrm{Na}$ colheita (37 DAS) não houve efeito significativo da interação dos tratamentos nos dois ambientes de cultivo, porém houve efeito dos tratamentos isoladamente. No ambiente protegido, com o aumento das doses de N, ocorreu efeito polinomial quadrático da área foliar, com incrementos até a dose estimada de $214,0 \mathrm{~kg} \mathrm{ha}^{-1}$, correspondente a 61152,4 $\mathrm{cm}^{2} \mathrm{~m}^{-2}$ (Figura 1A). No campo, a área foliar aumentou até $240 \mathrm{~kg} \mathrm{ha}^{-1}$ de $\mathrm{N}$, onde se observou valor estimado de $60987,5 \mathrm{~cm}^{2} \mathrm{~m}^{-2}$. Resultados de pesquisa mostrando valores de área foliar para a cultura, em função de adubação nitrogenada em cultivo no solo são escassos. Em cultivo hidropônico, Santamaria et al. (2002) observaram aumento na área foliar com o aumento da concentração de $\mathrm{N}$ na solução nutritiva de 1 para $8 \mathrm{mM}$, sendo que na maior concentração, verificaram 51200,0 cm² $\mathrm{m}^{-2}$.

O espaçamento entre plantas influenciou a área foliar nos dois ambientes de cultivo. As plantas cultivadas com 0,10 m apresentaram maiores médias, de $53600,0 \mathrm{~cm}^{2} \mathrm{~m}^{-2}$ e de $59131,4 \mathrm{~cm}^{2} \mathrm{~m}^{-2}$ respectivamente, em campo e ambiente protegido (Tabela 1). A redução da área foliar com a redução do espaçamento era esperada, pois segundo Castro et al. (1987) a diminuição do espaçamento entre plantas conduz à maior competição pelos fatores de crescimento como radiação solar, água e nutrientes limitando a expansão foliar.

A massa de matéria seca (MMS) aumentou com o incremento da dose de $\mathrm{N}$ até a dose estimada de 198,5 $\mathrm{kg} \mathrm{ha}^{-1}$ no campo e 186,3 $\mathrm{kg} \mathrm{ha}^{-1}$ no ambiente protegido, correspondendo aos valores estimados (MMS) de 203,1 e 209,1 g $\mathrm{m}^{-2}$, respectivamente (Figura $\left.1 \mathrm{~B}\right)$. Sabe- 

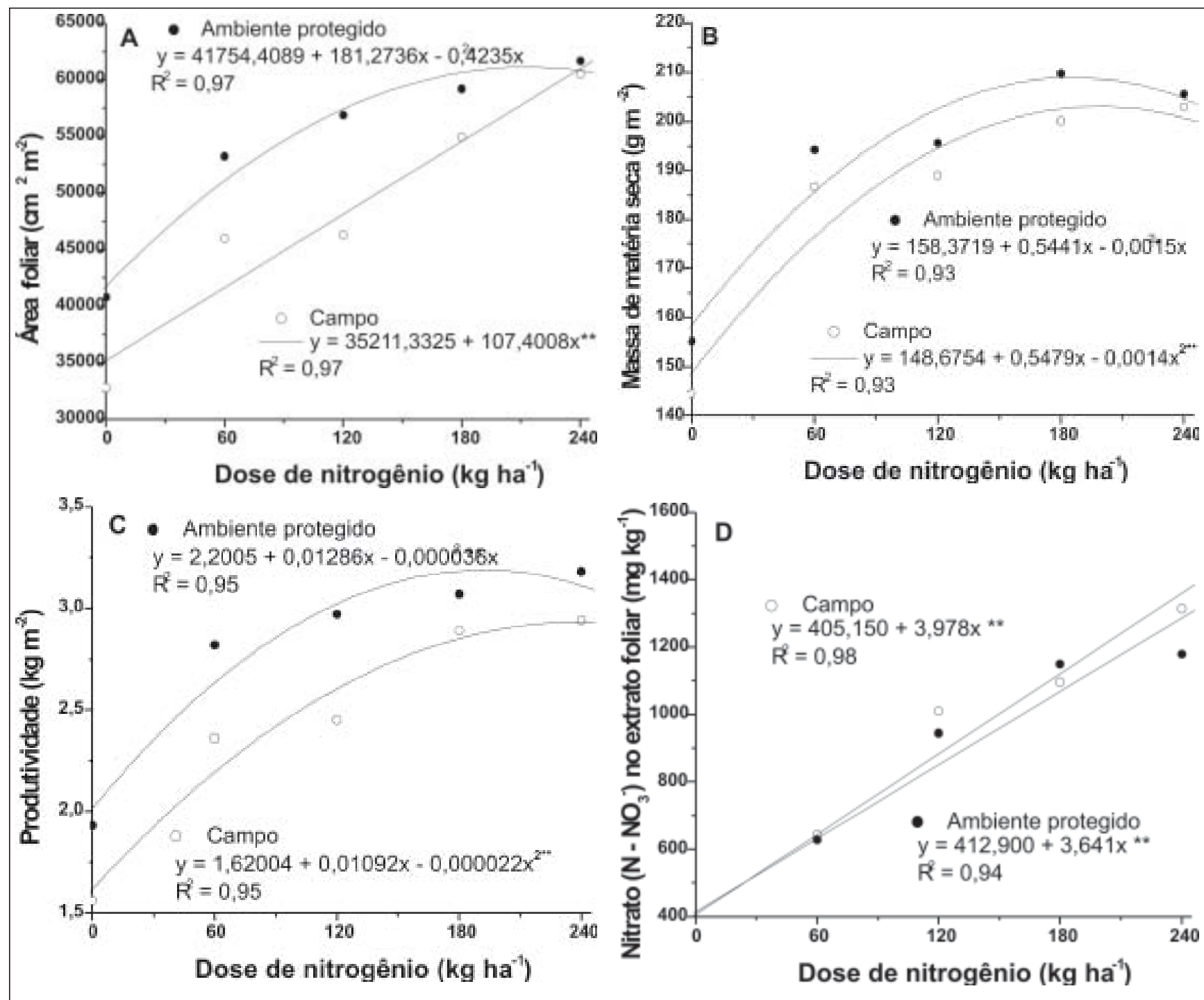

Figura 1. Área foliar (A), massa de matéria seca (B), produtividade (C) e teor de nitrato no extrato foliar (D) em rúcula cv. Folha Larga, em campo e ambiente protegido, no verão, em função de doses de nitrogênio (leaf area (A), dry mass weight (B), yield (C) and content of nitrate in leaves extract (D) of rocket salad cv. Folha Larga, in field and greenhouse, in summer, depending on N doses). FCA-UNESP, Botucatu, 2004.

se que o aumento da área foliar ou do dossel fotossintético, tem como objetivo promover melhor aproveitamento da energia solar relacionada com a geração de fotoassimilados e conseqüentemente com a geração de MMS. Trani et al. (1994) também observaram aumento na MMS estimada de plantas de rúcula com o aumento das doses de $\mathrm{N}$ de 0 para $240 \mathrm{~kg} \mathrm{ha}^{-1}$.

A MMS também variou com o espaçamento entre plantas. As maiores médias observadas foram de 210,3 e 214,9 $\mathrm{g} \mathrm{m}^{-2}$, respectivamente no campo e em ambiente protegido, com 0,10 m entre plantas (Tabela 1). De maneira semelhante ao observado para área foliar, a causa da menor produção de MMS verificada no espaçamento de 0,05 m entre plantas nos dois ambientes de cultivo, foi a competição entre plantas. Não existe uma padronização para a cultura da rúcula, que possibilite classificar se a área foliar e MMS, obtidas nos diferentes espaçamentos foram mais ou menos satisfatórias. Sabe-se que a preferência dos atacadistas e consumidores têm sido por maços com folhas grandes (Sala et al., 2004), porém esse fator depende do mercado consumidor. Para consumo in natura ou para uso no preparo de pizzas, prefere-se folhas tenras e com grande área, porém em restaurantes self-service prefere-se folhas tenras e pequenas. Dessa forma, os espaçamentos estudados possibilitam diferentes combinações de tamanho de planta e produtividade.

Na colheita, com o aumento das do- ses de $\mathrm{N}$ houve aumento na produtividade nos dois ambientes de cultivo até as doses estimadas de $240 \mathrm{~kg} \mathrm{ha}^{-1}$ no campo e $178,6 \mathrm{~kg} \mathrm{ha}^{-1}$ no ambiente protegido, correspondentes a 3,0 e 3,3 kg $\mathrm{m}^{-2}$ (Figura 1C). Resultados semelhantes foram observados por Trani et al. (1994), onde em campo, verificaram aumento de produtividade até a dose estimada de $188 \mathrm{~kg} \mathrm{ha}^{-1}$, correspondente a uma produtividade estimada de 1,7 $\mathrm{kg} \mathrm{m}^{-2}$. A dose de $\mathrm{N}$ em cobertura de 240 $\mathrm{kg} \mathrm{ha}^{-1}$ no cultivo de campo e de 178,6 $\mathrm{kg} \mathrm{ha}^{-1}$ no ambiente protegido, que proporcionaram maiores produtividades, encontram-se acima dos $120 \mathrm{~kg} \mathrm{ha}^{-1}$, recomendados por Trani \& Raij (1996). Porém, a dose no campo situou-se acima e em ambiente protegido abaixo da- 
Tabela 2. Produtividade (PROD) no campo (C) e área foliar e massa de matéria seca (MMS) de rúcula, cv. Folha Larga, em campo (C) e ambiente protegido (AP), no verão, em função do espaçamento entre plantas (yield (PROD) in field (C) and leaf area, dry mass weight (MMS) of rocket salad cv. Folha Larga, in field (C) and greenhouse (AP), in summer, depending on plant spacing). FCA-UNESP, Botucatu, 2004.

\begin{tabular}{|c|c|c|c|c|c|}
\hline \multirow[t]{2}{*}{ Tratamento } & \multicolumn{2}{|c|}{$\begin{array}{l}\text { Área foliar } \\
\left(\mathrm{cm}^{2} \mathrm{~m}^{-2}\right)\end{array}$} & \multicolumn{2}{|c|}{$\begin{array}{c}\text { MMS } \\
\left(\mathrm{g} \mathrm{m}^{-2}\right)\end{array}$} & \multirow{2}{*}{$\begin{array}{c}\begin{array}{c}\text { PROD } \\
\left(\mathrm{kg} \mathrm{m}^{-2}\right)\end{array} \\
\mathrm{C}\end{array}$} \\
\hline & C & AP & C & AP & \\
\hline $0,05 \mathrm{~m}$ & $16074,3 b^{1}$ & $37668,6 \mathrm{~b}$ & $62,9 \mathrm{c}$ & $148,6 \mathrm{~b}$ & $1,2 a^{1}$ \\
\hline $0,07 \mathrm{~m}$ & $17285,7 \mathrm{~b}$ & $44622,9 \mathrm{a}$ & $74,3 \mathrm{~b}$ & $171,4 \mathrm{a}$ & $1,0 \mathrm{~b}$ \\
\hline $0,10 \mathrm{~m}$ & $19182,9 \mathrm{a}$ & $44925,7 \mathrm{a}$ & $85,7 \mathrm{a}$ & $177,1 \mathrm{a}$ & $0,8 \mathrm{c}$ \\
\hline CV\% & 13,11 & 11,06 & 12,73 & 13,82 & 13,16 \\
\hline
\end{tabular}

${ }^{1}$ Médias na coluna, seguidas de mesma letra, não diferem entre si, pelo teste de Tukey (5\% probabilidade) (means in the column, followed by the same letter, did not differ from each other, Tukey's test, $\mathrm{p}<0.05$ ).

quela de $200 \mathrm{~kg} \mathrm{ha}^{-1}$ de $\mathrm{N}$, recomendada por Pimpini \& Enzo (1997) para o cultivo de rúcula em ambiente protegido com mais de um corte ou para o cultivo em solos arenosos. Dessa forma, as doses de $\mathrm{N}$ que ocasionaram a obtenção de máximas produtividades nesse estudo podem ser mais propícias às condições de solo arenoso.

No ambiente protegido a produtividade foi $12,4 \%$ maior que no campo. A maior produtividade verificada no campo, atingida com o uso de $240 \mathrm{~kg} \mathrm{ha}^{-1} \mathrm{de}$ $\mathrm{N}$, foi alcançada no ambiente protegido com apenas $110 \mathrm{~kg} \mathrm{ha}^{-1}$ de $\mathrm{N}$, ou seja, obteve-se uma economia de $130 \mathrm{~kg} \mathrm{ha}^{-1}$ de $\mathrm{N}$ no cultivo protegido.

A escolha da dose de $\mathrm{N}$ para a adubação da rúcula, nas condições ensaiadas, deve ser aquela que melhor atenda ao conjunto das características estudadas. Elegendo apenas como prioridade a maior produtividade, sugere-se o uso de $240 \mathrm{~kg} \mathrm{ha}^{-1}$ de $\mathrm{N}$ para o cultivo de campo e 178,6 kg ha-1 de N para o cultivo em ambiente protegido.

A produtividade de rúcula em função dos espaçamentos entre plantas, mostrou-se inversamente proporcional à área foliar e à MMS. A maior produtividade foi de 2,9 e 3,3 $\mathrm{kg} \mathrm{m}^{-2}$, respectivamente no campo e no ambiente protegido, no espaçamento de 0,05 m.

O teor de nitrato é um importante critério de avaliação de qualidade de hortaliças folhosas. O nitrato ingerido pelo ser humano contribui para a formação endógena de nitrosaminas que são compostos carcinogênicos, assim como é capaz de transformar a hemoglobina do sangue em ferrimoglobina, levando ao impedimento do transporte do oxigênio dos alvéolos pulmonares para os tecidos (Gangolli et al., 1994, citados por Santamaria et al., 1998). O aumento na dose de $\mathrm{N}$ proporcionou incremento linear no teor de nitrato no extrato foliar das plantas, nos dois ambientes de cultivo. Foram verificados os valores estimados de 1360 e $1290 \mathrm{mg} \mathrm{kg}^{-1}$ de $\mathrm{N}_{-} \mathrm{NO}_{3}{ }^{-}$nas plantas cultivadas no campo e no ambiente protegido, respectivamente (Figura 1D). Trani et al. (1994), em ensaio realizado em campo no outono, com $240 \mathrm{~kg} \mathrm{ha}^{-1}$, observaram o teor estimado de $1.070 \mathrm{mg}$ $\mathrm{kg}^{-1}$, valor inferior aos verificados no presente estudo. Em cultivo hidropônico, feito com a rúcula, Cavarianni (2004) observou na maior concentração de $\mathrm{N}$ na solução nutritiva (240 $\mathrm{mg} \mathrm{L}^{-1}$ ), teor estimado de $2.776 \mathrm{mg}$ $\mathrm{kg}^{-1}$ de $\mathrm{N}-\mathrm{NO}_{3}^{-}$, valor superior ao encontrado nos experimentos do presente estudo.

Maynard et al. (1976) e Graifenberg et al. (1993) afirmam que o conteúdo de nitrato na planta depende muito da sua disponibilidade no meio de cultivo. Dessa forma, poderiam ser explicados os maiores teores de nitrato no extrato foliar observados nas plantas submetidas às maiores doses de $\mathrm{N}$. Apesar de ainda não ter sido estabelecida uma faixa ideal de teor de nitrato para a rúcula, os maiores valores observados nas plantas nos dois ambientes de cultivo encontraram-se abaixo do limite permitido para a comunidade européia, para a cultura da alface. Segundo McCall \& Willunsen (1998) para a cultura da al- face produzida em casa de vegetação são permitidos teores máximos de $4.500 \mathrm{mg}$ $\mathrm{kg}^{-1}$ de massa fresca no inverno. Dessa forma as doses de $\mathrm{N}$ superiores à dose de $120 \mathrm{~kg} \mathrm{ha}^{-1}$ recomendada por Trani \& Raij (1996) para o cultivo de rúcula, nas quais se verificou as maiores produtividades, proporcionaram teor de nitrato no extrato foliar abaixo do limite citado para a alface e, provavelmente, não constituem risco à saúde humana.

Cultivo de verão - Durante o verão, a alta precipitação pluviométrica (367,5 $\mathrm{mm}$ ) durante o ciclo da cultura e sua concentração em curtos períodos de tempo foi prejudicial às plantas cultivadas no campo. O impacto das gotas de chuva nas folhas, bem como a movimentação de partículas de solo, danificaram as folhas, atrasando o desenvolvimento da planta e diminuindo a qualidade final do produto, a ponto de no momento da colheita, as folhas não apresentarem bom aspecto para a comercialização, pois estavam coriáceas, amareladas, danificadas e sujas. Dessa forma, as plantas cultivadas dentro do ambiente protegido beneficiaram-se de melhores condições, refletindo em maior crescimento, produtividade e qualidade de folhas, enfatizando assim a importância da utilização desse ambiente durante o verão.

Por ocasião da colheita constatouse efeito polinomial quadrático na área foliar das plantas cultivadas nos dois ambientes com aumentos até as doses estimadas de 240,0 e 203,5 $\mathrm{kg} \mathrm{ha}^{-1}$ de $\mathrm{N}$, respectivamente no campo e no ambiente protegido, correspondentes aos valores estimados de 21.746,0 e $50.772,2 \mathrm{~cm}^{2} \mathrm{~m}^{-2}$ (Figura 2A). No campo, as condições climáticas interferiram muito nas plantas contribuindo para a redução no ganho de área foliar.

Da mesma maneira ocorrida nos ensaios de outono/inverno, no maior espaçamento entre plantas observou-se maiores médias de área foliar, verificando-se 19182,9 e $44.925,7 \mathrm{~cm}^{2} \mathrm{~m}^{-2}$ no campo e no ambiente protegido, respectivamente (Tabela 2).

Houve resposta positiva das doses de $\mathrm{N}$ sobre a MMS das plantas onde ocorreu aumento até a dose de $240,0 \mathrm{~kg}$ ha $^{-1}$ no campo e $234,4 \mathrm{~kg} \mathrm{ha}^{-1}$ no ambiente protegido, correspondentes a 90,3 

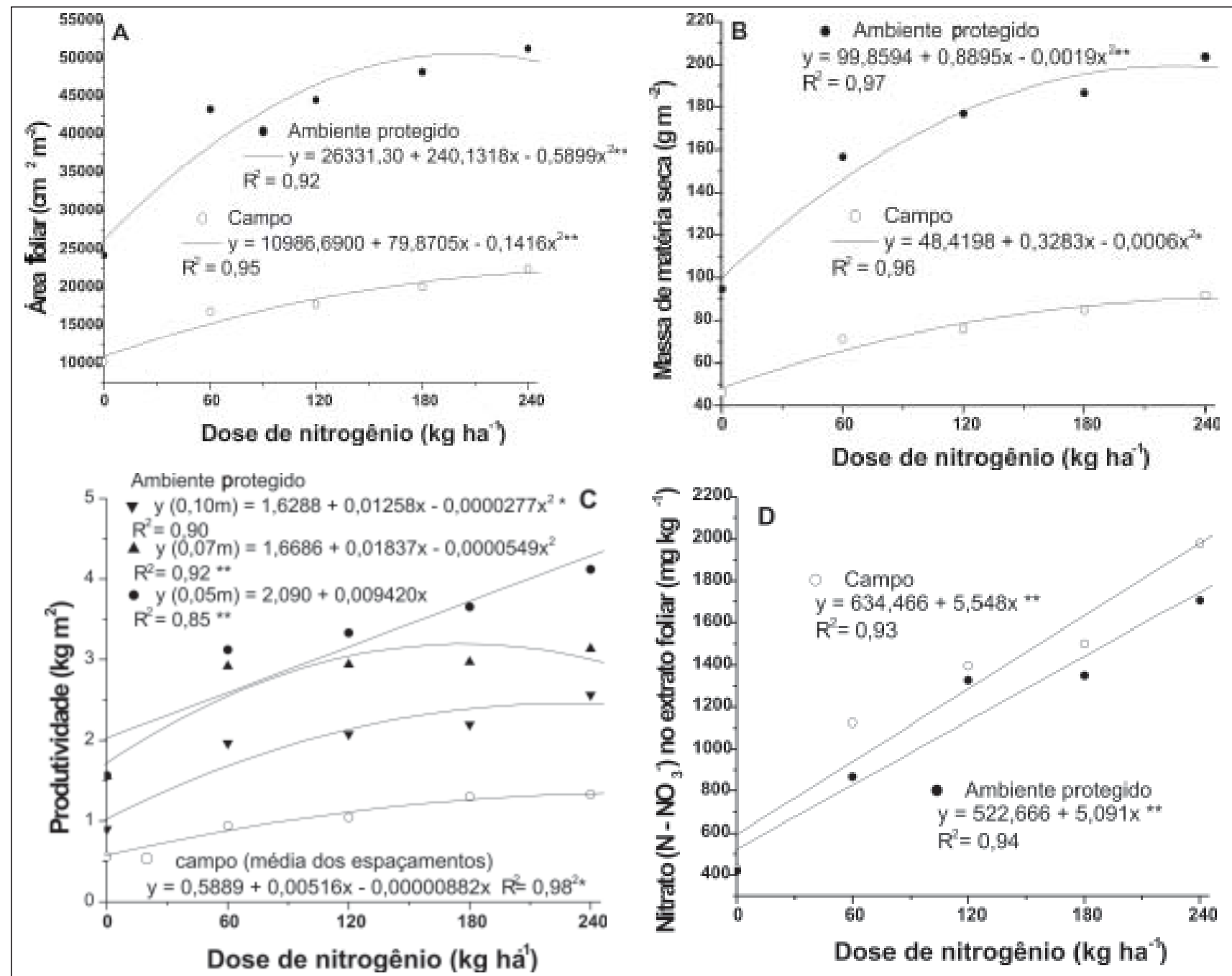

Figura 2. Área foliar (A), massa de matéria seca (B), produtividade (C) e teor de nitrato no extrato foliar (D) em rúcula cv. Folha Larga, em campo e ambiente protegido, no outono/inverno, em função de doses de nitrogênio (leaf area (A), dry mass weight (B), yield (C) and content of nitrate in leaves extract (D) of rocket salad cv. Folha Larga, in field and greenhouse, in autumn/winter, depending on N doses). UNESP, Botucatu, 2003.

e 203,9 $\mathrm{g} \mathrm{m}^{-2}$, respectivamente (Figura 2B). Com relação ao espaçamento entre plantas, as médias de 85,7 e $177,1 \mathrm{~g}$ $\mathrm{m}^{-2}$, respectivamente no campo e no ambiente protegido com $0,10 \mathrm{~m}$ entre plantas, foram as maiores observadas (Tabela 2). De maneira semelhante ao observado para área foliar e nos experimentos de outono/inverno a causa da menor produção de MMS verificada no espaçamento de 0,05 m entre plantas nos dois ambientes de cultivo, foi a competição que limitou o crescimento das plantas, de maneira que os espaçamentos estudados podem gerar diferentes combinações de tamanho de planta e produtividade.

Com relação à produtividade, no cultivo de verão, houve interação dos tratamentos estudados no ambiente protegido. Ocorreu aumento na produtividade para o espaçamento de $0,05 \mathrm{~m}$ entre plantas até a dose de $240 \mathrm{~kg} \mathrm{ha}^{-1}$ de $\mathrm{N}$, correspondendo a uma produtividade estimada de 4,3 $\mathrm{kg} \mathrm{m}^{-2}$ (Figura 2C). Para os espaçamentos de 0,07 e 0,10 m, ocorreu efeito quadrático na produtividade com o aumento das doses de $\mathrm{N}$ até 167,3 e $227 \mathrm{~kg} \mathrm{ha}^{-1}$, correspondentes a 3,2 e 2,4 $\mathrm{kg} \mathrm{m}^{-2}$, respectivamente. Nesses espaçamentos houve maior quantidade de $\mathrm{N}$ para o menor número de plantas, porém os processos de absorção iônica e metabolismo celular do nitrogênio, provavelmente chegaram ao limite. A interação dos tratamentos, ob- servado para as plantas cultivadas no ambiente protegido, pode ser devida ao efeito da densidade de plantas que afeta favoravelmente a curva de resposta à adubação nitrogenada, como observado por Coutinho et al. (1993).

No campo, a maior produtividade estimada foi de 1,3 $\mathrm{kg} \mathrm{m}^{-2}$ com $240 \mathrm{~kg}$ ha $^{-1}$ de N (Figura 2C). Essa produtividade foi inferior a de $2,3 \mathrm{~kg} \mathrm{~m}^{-2}$ verificada por Pereira et al. (2003) no campo em ensaio realizado no verão e superior ao ponto de inviabilidade de produção citada por Pegado et al. (2003). A produtividade e a qualidade das plantas verificadas no cultivo de campo foram insatisfatórias restringindo sua comercialização. Dessa forma, a 
produção de rúcula nesse ambiente, nas condições estudadas, torna-se muito pouco viável, principalmente se comparada à produtividade e qualidade no ambiente protegido.

Para o cultivo de verão, nas condições estudadas, sugere-se o uso de 240; 167,3 e $227 \mathrm{~kg} \mathrm{ha}^{-1}$ de $\mathrm{N}$, nos espaçamentos de 0,05; 0,07 e 0,10 m entre plantas, no ambiente protegido.

Os teores estimados de nitrato no extrato foliar verificados nas plantas cultivadas no campo e no ambiente protegido foram de respectivamente 1.966 e $1.744 \mathrm{mg} \mathrm{kg}^{-1}$ de $\mathrm{N}_{-\mathrm{NO}_{3}}^{-}$(Figura 2) e permaneceram abaixo do limite permitido pela comunidade européia para a alface (3.500 mg kg-1 no verão)

\section{AGRADECIMENTOS}

À FAPESP, pelo auxílio pesquisa concedido (2002/10105-0) e à CAPES pela concessão de bolsa de doutorado.

\section{REFERÊNCIAS}

BURT CM; O’CONNOR K; RUEHR T. 1995. Fertigation. San Luis Obispo: Polytechnic State University. 295 p.

CASTILLA N. 2005. Invernaderos de plásticoTecnologia y manejo. Madrid: Mundi Prensa. $462 \mathrm{p}$.

CASTRO PRC; FERREIRA SO; YAMADA T 1987. Ecofisiologia da produção agrícola. Piracicaba: Associação Brasileira para Pesquisa da Potassa e do Fosfato. 249 p.

CAMARGO LS. 1992. As hortaliças e seu cultivo. 3 ed. Campinas: Cargil. 252 p.

CAVARIANNI RL. 2004. Produção de cultivares de rúcula no sistema NFT e teores de nitrato. Dissertação Mestrado. 42p. Jaboticabal:
UNESP/FCAV.

CERMEÑO ZS. 1990. Estufas instalação e maneio. Lisboa: Litexa. 355p.

COUTINHO ELM; NATALE W; SOUZA ECA. 1993. Adubos e corretivos: aspectos particulares na olericultura. In: Anais do Simpósio Nutrição e Adubação de Hortaliças. Jaboticabal. Nutrição e adubação de hortaliças. Piracicaba: Potafos, p.141-146.

EMBRAPA. 1999. Centro Nacional de Pesquisa de Solos. Sistema brasileiro de classificação de solos. Brasília: Embrapa Solos.

ESPÍNDOLA CR, TOSIN WAC; PACCOLAAA. 1974. Levantamento pedológico da Faz. Experimental São Manuel. In: Cong. Bras. Ciência do solo. Santa Maria, p.650-651.

FILGUEIRA FAR. 2000. Novo manual de olericultura: agrotecnologia moderna na produção e comercialização de hortaliças. Viçosa. UFV, 402 p.

GRAIFENBERG A. 1993. Problematica dei nitrati. Infor. Agrar. Roma 6: 43-48.

GUSMÃO SAL. 2003. Cultivo de rúcula nas condições do Trópico Úmido em Belém. In: Anais do $43^{\circ} \mathrm{CBO}$. Horticultura Brasileira 21. 2003. Suplemento CD-ROM.

KATAYAMA MT. 1993. Nutrição e adubação de alface, chicória e almeirão. In: Anais do Simpósio sobre Nutrição e Adubação de Hortaliças. Jaboticabal. Nutrição e adubação de hortaliças. Piracicaba: Potafos, p.141-146.

MAYNARD DN. 1976. Nitrate accumulation in vegetables. Adv. Agron. 28: 71-118.

McCALL D; WILLUMSEN J. 1998. Effects of nitrate, ammonium and chloride application on the yield and nitrate content of soilgrown lettuce. Journal of Horticultural Science \& Biotechnology 73: 698-703.

MONDIN M. 1988. Influência de espaçamentos, métodos de plantio e de sementes nuas e peletizadas, na produção de duas cultivares de alface (Lactuca sativa L.). 1988. 59 f. (Tese mestrado) -UFLA, Lavras.

PEGADO DS. 2004. Densidade de plantio de rúcula, em sistemas de cultivo protegido. In: Anais do $44^{\circ} \mathrm{CBO}$, Horticultura Brasileira 22.
Suplemento CD-ROM.

PEREIREIRA ER; SILVA IJO; MOURA DJ. 2003. Alterações microclimática em túneis baixos com plástico perfurado no cultivo da rúcula em época de verão e de outono. Engenharia Agrícola 23: 407-414.

PIMPINI F; ENZO M. 1997. Present status and prospects for rocket cultivation in the Veneto region. In: PADULOSI S; PIGNONE D. Rocket: A mediterranean crop for the world. Report of a Workshop 13-14 dec. Plant Genetic Resources Inst., Rome, Italy.

SALA FC; ROSSI F; FABRI EG; RONDINO E; MINAMI K; COSTA CP. 2004. Caracterização varietal de rúcula. In: Anais do $44^{\circ} \mathrm{CBO}$. Hort. Bras., Campo Grande, 22. Suplemento CD-ROM.

SANTAMARIAP; ELIAA; PARENTE A; SERIO F. 1998. Fertilization strategies for lowering nitrate content in leafy vegetables: chicory and rocket salad cases. Journal of plant nutrition 21: 1791-1803.

SANTAMARIA P; ELIA A; SERIO F. 2002. Effect of solution nitrogen concentration on yield, leaf element content, and water and nitrogen use efficiency of three hydroponically-grown rocket salad genotypes. Journal of plant nutrition 25: 245-258.

SILVA MAB. 2004. GEAGESP. Seção de Economia. São Paulo-SP. Comunicação pessoal.

TAKAOKA M; MINAMI K. 1984. Efeito do espaçamento entre linhas sobre a produção de rúcula (Eruca sativa L.). O solo 2: 51-55.

TRANI PE; FORNASIER JB; LISBÃO RS. 1992. Cultura da rúcula. Campinas: IAC. n.146, 8p. (Boletim técnico 146).

TRANI PE; GRANJA NP; BASSO LC; DIAS DCFS; MINAMI K. 1994. Produção e acúmulo de nitrato pela rúcula afetados por doses de N. Horticultura Brasileira 12: 2529.

TRANI PE; RAIJ B. 1996. Hortaliças. In: RAIJ B. Recomendações de adubação e calagem para o estado de São Paulo. 2 ed. Campinas: IAC. p.157-186 (Boletim Técnico n. 100).

VILLAS BÔAS RL. 2003. UNESP/FCA. Recursos Naturais/Ciência do Solo. Botucatu-SP. Comunicação pessoal. 